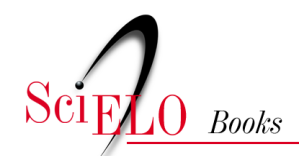

\title{
El proyecto piloto Namù Wökir: revitalización del bribri versus diglosia pedagógica en el ámbito escolar
}

\author{
Federico Guevara
}

\section{SciELO Books / SciELO Livros / SciELO Libros}

GUEVARA, F. El proyecto piloto Namù Wökir: revitalización del bribri versus diglosia pedagógica en el ámbito escolar. In: HABOUD BUMACHAR, M., SÁNCHEZ AVENDAÑO, C., and GARCÉS VELÁSQUEZ, F., eds. Desplazamiento lingüístico y revitalización: reflexiones y metodologías emergentes [online]. Quito: Editorial Abya-Yala, 2020, pp. 79-98. Desafíos en la Diversidad collection, n. 2. ISBN: 978-9978-10-541-2. http://doi.org/10.7476/9789978105726.0005.

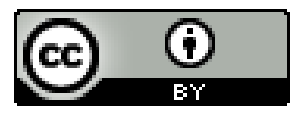

All the contents of this work, except where otherwise noted, is licensed under a Creative Commons Attribution 4.0 International license.

Todo o conteúdo deste trabalho, exceto quando houver ressalva, é publicado sob a licença Creative Commons Atribição 4.0.

Todo el contenido de esta obra, excepto donde se indique lo contrario, está bajo licencia de la licencia Creative Commons Reconocimento 4.0. 


\title{
El proyecto piloto Namù Wökir: revitalización del bribri versus diglosia pedagógica en el ámbito escolar
}

Federico Guevara'

\begin{abstract}
Resumen
Este artículo expone el proyecto desarrollado conjuntamente por la División de Educación Rural (DER) de la Universidad Nacional (UNA) de Costa Rica y la Dirección Regional Educativa de Sula' (DRE-Sula') en el caribe sur costarricense. Se trata de un proceso de fortalecimiento de habilidades de docentes de escuelas indígenas en una zona específica de Talamanca Bribri, donde, en la cotidianidad de las niñas y niños, se mantiene como primera lengua una variante del bribri. El proyecto promueve el uso del idioma indígena en el contexto escolar, no solo para su enseñanza, sino como instrumento de aprendizaje de otras asignaturas del currículo. Este surge del interés por generar propuestas de educación intercultural bilingüe que utilicen idiomas amerindios como auténticos recursos de aprendizaje en el ambiente escolar en distintas áreas disciplinares, lo que evitaría una especie de diglosia que promueve la asimetría entre el español como lengua de prestigio para el aprendizaje formal, frente a los idiomas indígenas en continuo desplazamiento, tal como ocurre en el actual sistema de educación indígena de Costa Rica.
\end{abstract}

\section{Introducción}

Esta contribución expone la experiencia investigativa desarrollada conjuntamente por la División de Educación Rural (DER) de la Universidad Nacional (UNA) de Costa Rica y la Dirección Regional Educativa de Sula' (DRE-Sula') en el caribe sur costarricense. Dicho proyecto, código 023016, es denominado: "Acompañamiento del plan piloto escolar NamuWokir: Aportes hacia una mejor educación intercultural bilingüe en Talamanca”. Se trata de un proceso de fortalecimiento de habilidades de docentes de escuelas indígenas en una zona específica de Talamanca Bribri, donde, en la cotidianidad

1 Universidad Nacional de Costa Rica. 
de las niñas y niños, se mantiene como primera lengua una variante del bribri. El proyecto promueve el uso del idioma indígena en el contexto escolar, no solo para su enseñanza, sino como instrumento de aprendizaje de otras asignaturas del currículo.

El fortalecimiento de las habilidades docentes comprende la organización y el planeamiento didáctico en contextos multigrado, así como la concientización fonológica del idioma bribri para la lectoescritura de la primera lengua (L1). Para ello, el proceso se aborda interdisciplinariamente con el aporte de profesionales en antropología, en pedagogía/planeamiento curricular y en lingüística. Surge del interés por generar propuestas de educación intercultural bilingüe que utilicen idiomas amerindios como auténticos recursos de aprendizaje en el ambiente escolar en distintas áreas disciplinares, lo que evitaría una especie de diglosia que promueva la asimetría entre el español como lengua de prestigio para el aprendizaje formal, frente a los idiomas indígenas en continuo desplazamiento, tal como ocurre en el actual sistema de educación indígena de Costa Rica.

\section{Políticas educativas dirigidas a poblaciones indígenas en Costa Rica}

La forma en que el Estado costarricense ha dictado políticas educativas para las poblaciones indígenas, ha respondido a transformaciones coyunturales relacionadas con cambios tanto en los paradigmas ideológicos como en el enfoque de derechos que cobija a estas poblaciones.

La historia de las políticas educativas vinculadas con población indígena en Costa Rica se puede clasificar en diversos periodos que, según Guevara y Solano (2017) se caracterizan así: 
81

- Modelo asimilacionista monolingüe (1886-1940). El Estado funda escuelas en zonas indígenas; primero en Amubrë, Talamanca Bribri, y luego en Boruca, Buenos Aires de Puntarenas. Entonces, se carecía de una política educativa diferenciada para las poblaciones indígenas, de forma que el modelo de escuela occidental establecido para el resto del país se extendió a estos contextos. El Estado se mostraba indiferente hacia preservar las lenguas indígenas, por lo que en estas escuelas se obligaba a aprender el español desde una visión monolingüe y etnocida.

- Modelo educativo basado en el indigenismo integracionista (1940-1985). Con el acuerdo internacional conocido como Convención de Pátzcuaro (1940), se establecen políticas sociales, administrativas, económicas y educativas para atender el "problema indígena". Al interior de los países firmantes se impuso el indigenismo integracionista como un enfoque que se esgrimió desde una perspectiva etnocéntrica, que concebía la cultura occidental como modelo prototípico. Para entonces, en Costa Rica, se crea la Junta Protectora de las Razas Aborígenes (JPRAN) como reguladora de todas las situaciones concernientes a los territorios indígenas; encargada, desde 1945, de fundar escuelas en dichas zonas. En 1950 se emite el Decreto ${ }^{\circ} 1$, con el que se insta a que el Ministerio de Educación y la JPRAN colaboraran para dictar planes de trabajo y disposiciones de carácter educacional. El modelo educativo propiciaba la transición hacia el español: lo importante era que las personas indígenas adquirieran la lengua oficial de la nación. En la práctica, hubo escasa tolerancia hacia las lenguas vernáculas: los maestros de esas escuelas reprimían al niño que usaba su idioma (Quesada, 1999). Durante la década de 
1950 se fundaron más escuelas en algunas zonas indígenas $\mathrm{y}$ varios docentes fueron enviados a formarse en el Instituto Indigenista Interamericano en México (UNICEF, 2012).

- Incentivación educativa bilingüe (1985-1992). En 1985 se crea la Asesoría Nacional de Educación Indígena; siendo la primera vez que el Ministerio de Educación Pública (MEP) establece una instancia administrativa exclusiva para la educación indígena. El decreto $\mathrm{n}^{\circ}$ 16619-MEP, con el cual se crea la Asesoría, menciona la importancia de tomar en cuenta el "contexto bicultural y bilingüe" de las comunidades amerindias. En el ámbito internacional, estos cambios corresponden con el viraje de enfoque hacia planteamientos educativos que resaltaban la importancia de tomar en cuenta los contextos lingüístico y cultural; de ahí que en algunos países latinoamericanos surja la educación intercultural bilingüe (EIB) (López, 2000). Para la época, en el ámbito internacional hay un fuerte ataque al paradigma del indigenismo integracionista, tanto desde el seno de las comunidades indígenas, cada vez más activas en la sociedad civil, como desde el sector académico (Batalla, 1981, 1987). Con la aparición del Convenio 169 de la OIT sobre Pueblos Indígenas, que deroga el anterior 107, se da un cambio en el enfoque de derechos que denota el creciente interés por promover la educación bilingüe y pluricultural.

- Consolidación y estancamiento del sistema de Lengua y Cultura (1993-2011). En 1992 la Asesoría de Educación Indígena se cierra de manera abrupta. Para el año siguiente se crea el Subsistema de Educación Indígena a través del decreto n²2072-MEP. Este instaba a enseñar a leer y a escribir en su propio idioma a los "miembros de las Reservas Indígenas”; pero a su vez, exigía la enseñanza del español 
como idioma oficial. Para 1994 el Ministerio de Educación Pública crea el Departamento de Educación Indígena (decreto $\mathrm{n}^{\circ} 23489$-MEP). A partir de entonces, este sería el encargado de diseñar, ejecutar y evaluar acciones curriculares dirigidas a la educación formal e informal de las comunidades indígenas.

- Para 1997, mediante la resolución 34-97 del Consejo Superior de Educación, se establecen formalmente las asignaturas de "Lengua Indígena", con tres lecciones semanales por nivel, y "Cultura Indígena", con dos lecciones por semana. Ese mismo año el Servicio Civil Docente crea los puestos de "Maestro de Lengua" y "Maestro de Cultura", con un código denominado "docentes de apoyo", lo que significa que estas personas completan su jornada laboral trabajando de manera itinerante en varias escuelas. Entre los objetivos del Programa de enseñanza de lenguas indígenas destaca: "Facilitar el proceso de transición de la lengua indígena al español, en aquellas comunidades donde la lengua indígena sea la lengua materna" (Rojas, 2002, p.181). Hasta hoy, las asignaturas de Lengua y Cultura existen con la misma distribución horaria, de manera que este modelo de educación bilingüe se ha estancado a pesar de los cambios de política educativa para pueblos indígenas.

- Hacia un sistema de educación intercultural bilingüe inclusivo (2011-2018). En el año 2009 se crea la primera Dirección Regional Educativa de carácter indígena, administrada por profesionales pertenecientes a los pueblos originarios bribris y cabécares, denominada Dirección Regional de Sula'. Su cobertura abarca los siete territorios indígenas bribris y cabécares de la vertiente atlántica del país. Para 2011 desaparece el antiguo Departamento de Educación 
Indígena y se crea el Departamento de Educación Intercultural, integrado por dos unidades: Educación Indígena -que asume las funciones del antiguo Departamento en cuanto a dirigir los programas de enseñanza de Lengua y Cultura, así como el asesoramiento del cuerpo docente de estas asignaturas - y Contextualización, Pertinencia Cultural. Para el año 2013 se emite el decreto 37801-MEP, conocido como "Reforma del subsistema de educación indígena"; la última política educativa de carácter oficial emitida por el Estado costarricense para pueblos indígenas; en el plano teórico, la de mayor alcance en cuanto al planteamiento de un modelo de Educación Intercultural Bilingüe de calidad. El enfoque de la nueva política trasciende la enseñanza de la lengua vernácula en el espacio escolar hacia la enseñanza en la lengua; es decir, utilizar el idioma indígena para facilitar diferentes asignaturas como un auténtico instrumento para el aprendizaje, independientemente del origen cultural de los contenidos escolares. Además, este decreto introduce importantes reformas en cuanto a la manera de seleccionar al personal docente, priorizando profesionales indígenas de cada contexto. Instituye la figura del Consejo Local de Educación Indígena para cada territorio, como una instancia local a través de la cual la comunidad participa más activamente en el servicio educativo, incidiendo tanto en la recomendación de nombramientos docentes como en la construcción de los currículos escolares con pertinencia cultural. Este último decreto se alinea con el enfoque de derechos promovido a través del Convenio 169 de la OIT, así como de la Declaración de Derechos de Pueblos Indígenas de la ONU de 2006. 
A pesar del decreto 37801-MEP sobre el uso del idioma indígena y la directriz de desarrollar programas bilingües en todas las asignaturas, modalidades y niveles del sistema educativo, se mantiene la disposición de otorgarle solo tres lecciones semanales a la asignatura de Lengua y dos a la de Cultura. Continúa el abrupto desequilibrio en el uso de la lengua indígena frente al español como idioma empleado para iniciar los procesos de alfabetización y enseñar todas las asignaturas del currículo escolar. Es decir, sigue sin materializarse un modelo que involucre transformaciones de fondo en términos curriculares, de mediación docente y de equilibrio entre ambas lenguas como instrumentos de igual importancia para los procesos educativos. En el escenario escolar, el español es la lengua de prestigio y de "conocimiento", mientras que el idioma indígena juega un papel subordinado.

Esta realidad pragmática puede ser descrita como una suerte de "diglosia pedagógica", partiendo del concepto de diglosia originalmente acuñado por Ferguson (1959) para referirse al uso disfuncional de dos variedades distintas de una misma lengua, ampliado por Fishman (1967), quien lo extiende a situaciones donde coexisten dos lenguas no emparentadas que cumplen funciones diferentes dentro de una comunidad de hablantes. En ese sentido, con "diglosia pedagógica" nos referimos al hecho de que, en la escuela, el español tiene una posición jerárquica relevante como principal instrumento para el aprendizaje de todas las asignaturas y contenidos escolares, mientras que el idioma ancestral se relega solamente a la clase de Lengua indígena, con una escaza distribución horaria sin ninguna función significativa en los procesos educativos formales, pese a que todavía hay contextos educativos donde el idioma indígena es la primera lengua de niñas y niños. 


\section{Namu Wokir: antecedentes, acciones y resultados}

Entre 2014 y 2016 se desarrolla el proyecto 0365-13 “Insumos para la construcción de un Observatorio para la Educación y la Cultura de los Pueblos Indígenas", adscrito a la División de Educación Rural (DER) del Centro de Investigación y Docencia en Educación (CIDE) de la Universidad Nacional (UNA). En el marco de dicho proyecto inicia la negociación con las autoridades educativas de la región indígena de Talamanca para el establecimiento del trabajo colaborativo alrededor de un plan piloto que le otorgara más protagonismo al idioma indígena en los procesos escolares. De forma paralela, se desarrolla un marco referencial que da cuenta del estado de la educación, la evolución histórica de las políticas educativas dirigidas a poblaciones indígenas a lo largo de sesenta años (Guevara \& Solano, 2017), y el planteamiento de una propuesta de planificación multilingüe que considere los escenarios lingüísticos existentes en los territorios indígenas de Costa Rica.

Para comenzar, se revisaron experiencias de educación intercultural bilingüe de países con mayor trayectoria en esta área, como Bolivia, Perú, Ecuador y México. El análisis de estas propuestas le permitió al equipo nutrirse teórica y metodológicamente, en aras de proponer un plan piloto en el contexto costarricense. Todas las experiencias consultadas aportaron positivamente, pero destacamos aquí el trabajo hecho por el Ministerio de Educación de Perú (2013), así como el Proyecto de educación intercultural bilingüe en escuelas p'urepecha del estado de Michoacán en México, en la que participaron la Universidad Autónoma Metropolitana (UAM) la Universidad Pedagógica Nacional (UPN), además de los docentes p'urepechas, referido en $\mathrm{Ha}$ mel (2001), Hamel et al. (2004) y en el video documental realizado por Trejo y Lizárraga (2010). De estas experiencias comprendimos la necesidad del enfoque interdisciplinario entre antropología, lingüísti- 
ca y pedagogía, la importancia de la iniciativa comunitaria y el trabajo horizontal con los docentes indígenas. Además, brinda evidencia científica de que la lengua ancestral puede servir no solo para construir conocimientos de la cultura propia, sino para aprender conocimientos universales; asimismo demostraba que la enseñanza de la lectoescritura en lengua indígena no constituía un obstáculo para la aprehensión correcta del español como segundo idioma.

Aunque en el ámbito de la lingüística, de la didáctica de lenguas, de la antropología lingüística y educativa esto es claro, aún existen muchos estereotipos en las comunidades, e incluso, algunos docentes indígenas e instituciones encargadas de la educación que sostienen que la alfabetización en el idioma ancestral es un obstáculo para aprender la lengua oficial. Por su parte, del trabajo del Ministerio de Educación de Perú comprendimos la importancia de ser sensibles al escenario sociolingüístico del estudiantado, para una correcta planificación bilingüe del currículo escolar, para la enseñanza de los idiomas, del aprendizaje de los conocimientos de todas las asignaturas en cada uno de estos, para la mediación docente en el ámbito escolar, entre otras.

Para empezar el proceso, se planteó la clasificación de los escenarios lingüísticos que podrían presentarse entre escolares de los pueblos y territorios indígenas del país. Esta propuesta se hizo tanto desde la experiencia peruana (Ministerio de Educación de Perú, 2013), como del estado de conservación y documentación de las lenguas indoamericanas en Costa Rica (Constenla, 2011).

Estos escenarios obedecen al desplazamiento lingüístico en cada comunidad específica, así como a la conservación de cada idioma en particular; de forma tal que en un mismo territorio indígena pueden coexistir varios escenarios lingüísticos. 


\section{Tabla 1 \\ Escenarios linguíísticos presentes en territorios indígenas de Costa Rica ${ }^{2}$}

\begin{tabular}{|l|l|}
\hline $\begin{array}{c}\text { Escenarios } \\
\text { lingüísticos }\end{array}$ & \multicolumn{1}{c|}{ Descripción } \\
\hline Escenario 1 & $\begin{array}{l}\text { Los niños y niñas tienen la lengua indígena como lengua } \\
\text { materna, esta predomina en la comunicación entre ellos y en } \\
\text { su comunidad. Pocos conocen algo de español. }\end{array}$ \\
\hline Escenario 2 & $\begin{array}{l}\text { Los niños y niñas tienen la lengua indígena como primer idio- } \\
\text { ma, pero manejan el español y se comunican aceptablemente } \\
\text { en ambas. Las usan indistintamente o en situaciones diferen- } \\
\text { ciadas (en la familia o comunidad usan la lengua indígena y } \\
\text { en otros lugares como poblados aledaños o con personas no } \\
\text { indígenas, usan el español). Esto se reproduce en el aula con } \\
\text { ciertas diferencias en los grados de bilingüismo del estudian- } \\
\text { tado. Puede haber estudiantes bilingües de cuna, es decir, que } \\
\text { aprendieron a hablar dos lenguas desde el nacimiento. }\end{array}$ \\
\hline \multirow{1}{*}{ Escenario 3 } & $\begin{array}{l}\text { Los niños y niñas hablan español como primera lengua, pero } \\
\text { comprenden o hablan de manera incipiente el idioma indí- } \\
\text { gena. Sus padres y abuelos todavía se comunican entre ellos } \\
\text { en la lengua originaria, pero se dirigen a los niños en espa- } \\
\text { ñol. Algunos estudiantes están familiarizados con la lengua }\end{array}$ \\
\hline
\end{tabular}

2 Hay un escenario más, en el cual el niño o niña convive en un contexto bilingüe con dos lenguas indígenas. Esto pasa con el bribri y cabécar en una zona muy específica de Talamanca, y también con el ngäbere y buglere en algunas familias, principalmente en los territorios indígenas de Coto Brus, Altos de San Antonio y Osa. Es un escenario muy particular, localizado en pequeñas zonas geográficas, por lo que es necesario un diagnóstico sociolingüístico especial que dé cuenta de la complejidad de este en cada caso particular, pero también es necesario respetar el deseo y sentir de la comunidad educativa involucrada sobre cómo atender esta realidad en el proceso escolar. 


\begin{tabular}{|l|l|}
\hline \multirow{5}{*}{ Escenario 4 } & $\begin{array}{l}\text { indígena, eventualmente la usan, pero puede existir una valo- } \\
\text { ración negativa de esta. Sin embargo, el contexto es favorable } \\
\text { para el aprendizaje del idioma indígena como segunda len- } \\
\text { gua (L2) o el desarrollo de bilingüismo. }\end{array}$ \\
\hline $\begin{array}{l}\text { Los niños y niñas hablan solo español, la lengua indígena } \\
\text { ha sido desplazada casi completamente. En estos lugares, la } \\
\text { posibilidad de adquisición de la lengua indígena es muy li- } \\
\text { mitada, solo es hablada por los abuelos en situaciones espo- } \\
\text { rádicas. La funcionalidad de la lengua es casi nula. Se puede } \\
\text { desarrollar en la escuela el aprendizaje de la lengua indígena } \\
\text { como segunda lengua (L2). }\end{array}$ \\
\hline Escenario 5 & $\begin{array}{l}\text { Los niños y niñas hablan solo español. La lengua indígena } \\
\text { carece de hablantes fluidos, solo existen algunos semifluidos. } \\
\text { La funcionalidad de la lengua es casi nula, aunque puede } \\
\text { haber un uso simbólico, con cierto manejo del léxico. Sin } \\
\text { embargo, el estado de documentación de la lengua indígena } \\
\text { permite su enseñanza; en la escuela puede desarrollarse su } \\
\text { aprendizaje como segunda lengua (L2). }\end{array}$ \\
\hline Escenario 6 & $\begin{array}{l}\text { Los niños y niñas hablan solo español. La lengua indígena } \\
\text { desapareció hace mucho tiempo. Se carece de suficiente do- } \\
\text { cumentación, por lo que es imposible generar enseñanza bi- } \\
\text { lingüe. De momento, solo existe un limitado léxico de flora, } \\
\text { fauna, toponimia y nombres propios. }\end{array}$ \\
\hline
\end{tabular}

Adaptado de Guevara y Solano (2017).

Para materializar el plan piloto, se generó un profundo proceso de negociación entre el equipo académico de la UNA y la Dirección Regional Educativa de Sula (DRE). En este proceso se perfiló de manera conjunta cuál era el modelo de escuela deseado, cuáles eran las posibilidades de una educación bilingüe intercultural que le diera más presencia y protagonismo al idioma indígena, qué perfil 
de docente se requería, qué perfil de estudiante se esperaba y cuál sería el papel de la comunidad. Para abril de 2014, la posibilidad de generar un proyecto escolar piloto se había consolidado.

A lo largo del 2015 se llevaron a cabo reuniones de trabajo entre el equipo en esa línea. El perfil de comunidad y de escuela donde se incursionaría con la experiencia debía reunir las siguientes características: 1. Que los estudiantes de la escuela tuvieran el idioma indígena como primera lengua, 2. Que los maestros del centro educativo fueran en su mayoría hablantes de la lengua indígena, 3 . Que el equipo de la escuela tuviera compromiso con el proceso de desarrollo del proyecto, y 4. Que la comunidad contara con individuos que ostentaban cargos tradicionales de la cultura indígena (médicos tradicionales, maestros de ceremonias, cantores, etcétera). Finalmente, se seleccionó la escuela Namu Wökir en el circuito escolar 02 de la región educativa, con población indígena bribri.

La selección de Namu Wökir fue sometida a consulta comunitaria en un taller efectuado el 27 de mayo de 2015 en Amubrë, con amplia participación de representantes de diferentes sectores de las comunidades de la región de Talamanca. Finalizado el proceso de consulta, se realiza un diagnóstico sociolingüístico de la comunidad Namu Wökir. Este se efectuó durante setiembre del año 2015 con una combinación de técnicas: observación participativa en el centro educativo, un cuestionario por hogar en veintiún viviendas ${ }^{3}$ (dieciséis ubicadas en la zona baja y cinco en la montañosa) para conocer cuál era el uso de los idiomas español y bribri en diferentes situaciones comunitarias, determinar el empleo de estas lenguas en distintas generaciones (niñas, niños, padres, madres, abuelas, abuelos), y

3 El total de viviendas asciende a sesenta. 
cuáles eran las habilidades comunicativas que presentaban en ambos idiomas (hablar, comprender, leer, escribir), entre otras.

Los principales resultados obtenidos de esta encuesta son los siguientes:

- El idioma bribri es el más utilizado en los hogares 100 por ciento en el caso de abuelas-abuelos, 100 por ciento en el caso de padres-madres y 95 por ciento en el caso de niñas-niños).

- El idioma español se usa de manera regular en el hogar: un 36 por ciento de los padres-madres y cerca del 73 por ciento de las niñas-niños. Solamente un 23 por ciento de las abuelas-abuelos usan el español y en muy pocas ocasiones.

- En actividades comunitarias, los tres grupos generacionales contestaron que el idioma bribri es el más usado. Cerca de la mitad de los padres, madres, niñas y niños dijeron que usaban el español de manera regular en algunas actividades comunitarias.

- Las abuelas y abuelos son quienes tienen menores habilidades comunicativas en español.

- Con respecto a la lectoescritura, la generación de mayor edad solo un 4,7 por ciento sabe leer y escribir en español, pero ninguno lee o escribe en bribri. Del grupo de padresmadres, un 52,3 por ciento sabe leer y escribir en español, pero solo un 23,8 por ciento de ellos lee y escribe en bribri; mientras que en el grupo de niñas-niños, el 85,7 por ciento sabe leer y escribir en español y el 42,8 por ciento dice saber hacerlo también en bribri. Estos resultados coinciden con las políticas educativas aplicadas a las poblaciones indígenas en diferentes momentos históricos. 
Con base en los datos analizados y la categorización de escenarios lingüísticos, se estima que para el caso de Namu Wökir estamos frente a una combinación de escenarios lingüísticos $\mathrm{n}^{\circ} 1$ y 2 . Establecer estos escenarios posibilita un planteamiento curricular acorde con su realidad, donde el uso de la primera (L1) y la segunda lengua (L2) responda a las necesidades de la comunidad educativa.

Es necesario destacar que el idioma bribri cuenta con unos 6000 hablantes; según el criterio lingüístico, se encuentra en un estado de resistencia/declinación (Constenla, 2011). Es una de las lenguas indígenas más documentadas del país; si bien tiene un abecedario oficial, no es un idioma estandarizado.

A partir del año 2017 entra en vigencia el proyecto 0230-16 para acompañar el plan piloto en Namu Wökir. En esta comunidad el centro educativo cuenta con categoría de "Dirección 1 multigrado", lo cual quiere decir que tiene un director que funge también como docente, además de otro maestro regular. Ambos atienden varios niveles simultáneamente. También se cuenta con los docentes de apoyo de las materias de Lengua y Cultura y una docente de educación prescolar. La escuela recibe cerca de 50 niños y niñas. En promedio, a los niños de las casas más alejadas les toma entre una y dos horas llegar a la escuela.

Si bien es cierto, Namu Wokir fue la comunidad educativa elegida para el plan piloto, por iniciativa del supervisor del circuito 02 de la Región Educativa de Sula', se incorporaron siete escuelas más, pues según su criterio, reúnen las mismas características y presentan una situación lingüística similar a la diagnosticada en Namu Wökir. Actualmente se trabaja con personal de las escuelas de Namu Wökir, Alto Katsi, Bris, Alto Urén, Alto Kachabri, Duchabri, Tsoki y Duriñak.

A lo largo de 2017 se desarrolló un taller mensual con el cuerpo docente; así, se dio continuidad al fortalecimiento de la organi- 
zación y planeamiento de la escuela multigrado, temas trabajados desde el proyecto anterior; además, se inicia con una serie de talleres de concientización fonológica, los cuales han constituido un gran aporte para el grupo de docentes de las escuelas participantes, pues aunque estas personas son hablantes de la lengua indígena, sus habilidades en cuanto a su escritura eran desiguales, y se carecía de acuerdos en cuanto a ciertas inconsistencias que se manifiestan en lenguas no estandarizadas, como es el caso del bribri.

A finales del año 2017 se generan importantes resultados en una de las escuelas participantes del proyecto. En la escuela de Duchabri el trabajo complementario entre la docente regular y la docente de Lengua logra que los niños del primer nivel de escuela aprendan a leer y escribir en bribri. Este resultado es significativo, ya que en Costa Rica normalmente el proceso de lectoescritura de niños cuya primera lengua es indígena, se alcanza hasta el segundo o tercer nivel de la escuela, dado que se impone la lectoescritura del español desde el primer grado y las clases de Lengua indígena tienen poca carga horaria semanal; además, el programa oficial de esta asignatura carece de estrategias pertinentes para la enseñanza de las habilidades de lectoescritura.

El mérito del logro en Duchabri es mayor, dado que la docente regular no es hablante fluida del bribri, por lo que tuvo que trabajar con la docente de Lengua, quien, para ello, dedicó horas adicionales a su jornada. De esta forma, combinaron el método fonético con el global; elaboraron carteles de imágenes de elementos concretos tomados de la realidad inmediata de los niños y niñas para ilustrar cada uno de los sonidos de las letras; además construyeron un diccionario con carteles de experiencia para generar ejercicios de lectura y producción escrita a partir de palabras simples conocidas por sus estudiantes. 
El trabajo de estas docentes estuvo siempre respaldado por el director del centro educativo, lo cual ejemplifica la importancia del involucramiento de la comunidad educativa para el éxito de un proyecto. Aunque los padres y madres de familia inicialmente mostraron algunas dudas sobre iniciar la lectoescritura en bribri en lugar de español, estas se disiparon al comprobar que al finalizar el primer nivel de escuela el alumnado estaba alfabetizado en ambas lenguas.

Los docentes regulares de las escuelas participantes del proyecto siempre han echado mano del idioma indígena para impartir varias de sus lecciones, principalmente con los primeros niveles, donde los niños y niñas aún no han adquirido suficientes habilidades comunicativas en español, ya que, en sus propias palabras: "una lección en español es una lección perdida con estos chicos". Esto fue un factor positivo para el proceso, pues las personas docentes, por iniciativa propia, ya le daban espacio al idioma indígena en el contexto escolar más allá del tiempo lectivo estipulado para la asignatura de Lengua.

No obstante, desde el proyecto se plantea que el idioma indígena debe planificarse en distintas asignaturas de manera formal; es decir, esta acción debe ordenarse desde un planeamiento curricular que considere las particularidades de un escenario multigrado, donde la organización del espacio, del tiempo y del alumnado es distinta de un espacio escolar con estudiantes de un único nivel. Asimismo, es necesario construir estrategias y materiales didácticos en el idioma indígena para las diferentes asignaturas. Para 2018, la línea de trabajo del proyecto apunta hacia estas metas.

Para el año 2019 se continúa con la producción de material didáctico desde un planeamiento equilibrado del bribri y el español en todo el currículo escolar; también se planifican pruebas en escuelas control que no están dentro del proyecto, lo que permiti- 
ría comparar el rendimiento académico del estudiantado en varias asignaturas, incluidas las habilidades comunicativas de la primera y segunda lengua.

\section{Reflexiones finales}

Pensar en lenguas en desplazamiento, entendidas como idiomas que sufren un proceso mediante el cual los usuarios individuales de un idioma o variedad lingüística reemplazan su uso por otra a causas de múltiples razones (que pueden ir desde políticas lingüísticas, opresión cultural, cambio religioso, migraciones, etcétera), es pensar en contextos donde se da el fenómeno del bilingüismo. El bilingüismo, entendido como la capacidad que tiene un individuo de comunicarse con eficacia en dos lenguas distintas y alternadamente, debe considerarse como un fenómeno con dos vertientes: una individual y otra social (Lamounier, 2013).

El desplazamiento de un idioma, como concepto, tiene varias ventajas. Por un lado, rompe con el posicionamiento clásico de "muerte de lenguas" o "lenguas extintas"; e implica factores "extralingüísticos" que inciden directamente sobre este fenómeno, como los contextos social y cultural. También, hablar de una lengua desplazada remite a otro idioma desplazante, lo que nos recuerda que este suceso se adscribe a un escenario de relaciones de poder.

En una situación de lenguas en desplazamiento, la institución escolar debe jugar un papel diferente del que tradicionalmente ha mantenido. Históricamente, la escuela ha sido un factor de desplazamiento lingüístico y de etnocidio (destrucción de tradiciones y patrones culturales) en diferentes regiones indígenas del continente americano. Para el caso de Costa Rica, si bien las actuales políticas educativas promueven la enseñanza dely en el idioma indígena para 
todos los niveles y asignaturas; en la práctica, el sistema educativo formal reproduce una diglosia pedagógica que relega terriblemente estas lenguas de la acción educativa.

El proyecto piloto Namu Wökir representa un esfuerzo porque la escuela se convierta en un espacio promotor del bilingüismo aditivo, en el sentido que Lambert (1974) le daba a esta noción: convivencia de dos lenguas en equilibrio en un ambiente social que promueve el aprendizaje en ambos idiomas con enriquecimiento cultural. Consideramos que el hecho de que la lengua indígena gane espacio en el contexto escolar constituye un avance que coadyuva a la revitalización lingüística. Ciertamente, revertir una situación de desplazamiento lingüístico sobrepasa las posibilidades de un proyecto escolar, en vista de la complejidad de este fenómeno y de los factores sociales, políticos y culturales que lo alimentan. Sin embargo, cuando una comunidad se compromete a luchar por la revitalización de su lengua originaria, pasos como el expuesto en este documento pueden engranarse positivamente con otras acciones y ámbitos.

\section{Referencias bibliográficas}

Bonfil, G. (1981). Utopía y revolución: El pensamiento político contemporáneo de los indios en América Latina. México: Editorial Nueva Imagen.

(1987). Los pueblos indios, sus culturas y las políticas culturales. En García Canclini (Ed.), Las politicas culturales en América Latina (pp. 89-126). México: Grijalbo.

Constenla, A. (2011). Estado de conservación y documentación de las lenguas de América Central pertenecientes a las agrupaciones jicaque, lenca, misumalpa, chibchense y chocó. Revista de Filología y Lingüistica de la Universidad de Costa Rica, 37(1), 135-195.

Fishman, J. (1967). Bilingualism with and without diglossia, diglossia with and without bilingualism. Journal of Social Issues, 23(2), 29-38.

Ferguson, C. (1959). Diglossia. Word, 15, 325-340. 
Guevara, F., Nercis, I., \& Ovares, S. (2015). Los docentes de Lengua y Cultura: una mirada reflexiva y crítica de la educación indígena costarricense. Revista Electrónica Educare, 19(2), 317-332. http://dx.doi.org/10.15359/ ree.19-2.18

Guevara, F., \& Solano, J. (2017). La escuela y los pueblos indígenas de Costa Rica: Politicas, indicadores educativos y planificación multilingüe. San José: Universidad Nacional.

Hamel, R. (2001). Políticas del lenguaje y educación indígena en México. Orientaciones culturales y estrategias pedagógicas en una época de globalización. En Bein, R. y Born, J. (Eds.), Politicas lingüisticas. Norma e identidad (pp. 143-170). Buenos Aires: UBA.

Hamel, R., Brumm, M., Carrillo Avelar, A., Loncon, E., Nieto, R., \& Silva Castellón, E. (2004). ¿Qué hacemos con la Castilla? La enseñanza del español como segunda lengua en un currículo intercultural bilingüe de educación indígena. Revista mexicana de investigación educative, 9(20), 83-107.

Lambert, W. (1974). Culture and language as factors in learning and education. En Aboud, F. y Meade, R.D. (eds.). Cultural Factors in Learning and Education. Bellingham Washington: Fifth Western Washington Symposium on Learning.

Lamounier, A. (2013). ¿En cabécar o español? Bilingüismo y diglosia en Alto Chirripó. Cuadernos Intercambio, 10(12), 105-119.

López, L. (2000). La cuestión de la Interculturalidad y la educación latinoamericana. Documento presentado al Seminario sobre prospectivas de la Educación en la Región de América Latina y el Caribe, Oficina Regional de Educación de la Organización de Naciones Unidas para la Educación y la Cultura, Santiago, Chile. Recuperado de: http://adei.org.pe/anexos/ Interculturalidad/cuestion_latinoamericana.pdf

Ministerio de Educación de Perú (2013). Hacia una educación intercultural bilingüe de calidad. Propuesta pedagógica. Lima: Cecosami Pre Prensa e Impresión Digital S.A.

Programa Estado de la Nación en Desarrollo Humano Sostenible (Costa Rica) (2013). Cuarto Informe Estado de la Educación. San José: Editorama.

Quesada, M. (1999). Situación actual y futuro de las lenguas indígenas de Costa Rica. Estudios de Lingüistica Chibcha, XVIII-XIX, 7-34.

Rojas, C. (2002). La enseñanza de las lenguas indígenas en Costa Rica. Educare, 3, 177-186. Recuperado de: http://www.revistas.una.ac.cr/index.php/ EDUCARE/article/viewFile/997/921 
Trejo, G., \& Lizárraga, C. (2010). T’arhexperakua. Investigación-acción colaborativa y educación intercultural bilingüep'urhepecha [video]. México: UAM-UPN.

UNICEF (2006). Niñez y Adolescencia indigena en Costa Rica: su derecho a la salud y a la educación. San José: UNICEF.

(2012). Situación de los docentes en territorios indígenas de Costa Rica. San José: Fondo de las Naciones Unidas para la Infancia. 